ARTIGO

Recebido em: 05/08/2017

Aceito em: 04/12/2017

\title{
Projeto educativo para competências em informação: bases teóricas para a pesquisa-ação em uma biblioteca multinível
}

\author{
Educational project for information literacy: \\ theoretical bases for research in a multilevel library
}

\author{
Jobson Louis Santos de ALMEIDA (jobsonlouis@gmail.com)* \\ Gustavo Henrique de Araújo FREIRE (ghafreire@gmail.com)** \\ * Bibliotecário - IFPB. \\ ** Professor em Biblioteconomia - UFRJ; Professor do Programa de Pós-Graduação em Ciência da \\ Informação - UFPB.
}

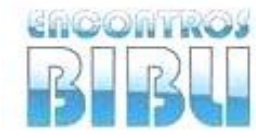

v. 23, n. 51,2018 . p. $123-137$

ISSN 1518-2924

\begin{abstract}
From the training to the education of users, much has been done to make the library a learning space in the last decades, but lack theoretical demonstrations in the scientific literature to present the relevance of the management of educational projects allied to a learning organizational philosophy for the development of information skills. This article is the result of a research carried out at a master's level in the multilevel library of one of the units of the Federal Institute of Paraiba. It presents theoretical bases for understanding the development of information skills as an activity based on educational project and the importance of action research in this process. The research that originated this work is delineated as action research, of qualitative nature and exploratory-descriptive level. It concludes that the constitution of the educational project contributes in the process of transforming the conventional library into a learning library and that the application of the educational project, its monitoring and its evaluation can reveal the possibilities and limitations of the process in relation to the information regime.
\end{abstract}

Keywords: Information Literacy. Educational Project. Action-Research.

Resumo: Do treinamento à educação de usuários, muito se têm feito para tornar a biblioteca literatura científica para apresentar qual a relevância da gestão de projetos educativos aliada a uma filosofia organizacional aprendente para o desenvolvimento de competências em informação. 0 presente artigo é fruto de pesquisa realizada em nível de mestrado na biblioteca multinível de uma das unidades do Instituto Federal da Paraíba. Apresenta bases atividade baseada em projeto educativo e a importância da pesquisa-ação neste processo. A pesquisa que originou este trabalho é delineada como pesquisa-ação, de natureza qualitativa e de nível exploratório-descritivo. Conclui que a constituição do projeto educativo contribui que a aplicação do projeto educativo, seu monitoramento e sua avaliação podem revelar as possibilidades e limitações do processo em relação ao regime de informação.

Palavras-chave: Competências em informação. Projeto educativo. Pesquisa-ação.

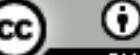




\section{INTRODUÇÃo}

0 presente artigo é fruto de pesquisa realizada em nível de mestrado sobre o desenvolvimento de competências em informação na biblioteca multinível de uma das unidades do Instituto Federal de Educação da Paraíba (IFPB). A pesquisa apontou para a escassez de literatura científica sobre a biblioteca como organização aprendente. Observou-se que esta é uma abordagem recente, surgida no início dos anos 2000, introduzida na literatura científica brasileira por Dudziak (2001) ao discorrer sobre a "information literacy", conceito este que em sua tradução para a língua portuguesa no Brasil compreendemos como "competência em informação", tanto para fins deste estudo, quanto em concordância com a visão de outros pesquisadores consagrados no campo das Ciências Sociais Aplicadas e da Educação, a exemplo de Belluzzo, Caregnato, Hatschbach, Freire e outros contemporâneos.

Neste sentido, percebemos que as bibliotecas podem fornecer vantagem competitiva para as instituições de ensino, sobretudo no tocante ao desenvolvimento de competências em informação. Corroborando com Maponya (2004), o sucesso das bibliotecas depende da habilidade de utilizar a informação e o conhecimento de sua equipe de profissionais colaboradores para atender e resolver as necessidades de uma comunidade acadêmica. Acrescentando a esta visão, temos a percepção nítida de que a informação é um elemento indubitavelmente natural das organizações, e que a competência - entendida como associação de conhecimentos, habilidades e atitudes para conquistar um resultado diferenciado, corroborando com Nisembaum (2001) - deve ser estimulada e desenvolvida nos usuários da biblioteca, para que estes conquistem cada vez mais autonomia intelectual para trabalhar com a informação e produzir conhecimento.

A informação, aliada ao conhecimento, é de suma importância para o desenvolvimento da sociedade contemporânea e, consequentemente, para as organizações, a partir do momento em que a mesma é gerida como um valor estratégico determinante e um bem que deve ser compartilhado. Para que uma biblioteca alcance, portanto, o status de ser considerada uma organização aprendente, acredita-se que seria necessário, respectivamente: o desenvolvimento, a implementação e o fortalecimento de uma nova filosofia organizacional condutora dessas ações de aprendizagem, sem dissociar deste contexto, o desenvolvimento de competências em informação, que é inerente a sua natureza e necessário numa sociedade baseada em informação, conhecimento e aprendizagem.

Muitos bibliotecários consideram-se educadores, possuindo inclusive capacidade para tal, conforme aludido por Dudziak (2003, p. 32), mas não tem sido fácil para estes serem percebidos e reconhecidos como bibliotecários educadores no contexto organizacional em que estão inseridos. E como têm sido com os bibliotecários da Rede Federal de Educação Profissional, Científica e Tecnológica (Rede Federal EPCT)? Pois embora esta tenha pouco mais de um século de existência, em 2008 sofreu uma grande mudança, assumindo uma nova e complexa configuração com a criação dos Institutos Federais de Ensino. Há algo de diferente na biblioteca desse novo contexto? Ou seria ela igual a biblioteca escolar e a biblioteca universitária? Repensar sobre o papel do bibliotecário e da biblioteca neste inédito contexto é necessário e colabora para responder as questões até então levantadas neste trabalho.

\section{A BIBLIOTECA COMO ORGANIZAÇÃO APRENDENTE}

0 papel educacional do bibliotecário e da biblioteca diante dos serviços de informação e demandas emergentes ganham maior relevância e destaque no contexto desafiador dos recém-criados Institutos Federais. Do treinamento à educação de usuários, muito se têm feito ao longo da história para tornar a biblioteca um espaço de aprendizagem, mas seriam suficientes as práticas já 
realizadas por esses outros tipos de bibliotecas? Faltam demonstrações teóricas para explicar a este novo perfil de bibliotecários por onde começar, o que e como fazer para desenvolver competências em informação.

Nas bibliotecas aprendentes, a gestão do conhecimento aliada à cultura da aprendizagem organizacional são fatores que impulsionam a inovação gerencial, possibilitando excelência e qualidade no desempenho organizacional. A sustentabilidade imbuída neste contexto torna essa perspectiva uma filosofia e prática de gestão possível. As bibliotecas de instituições de ensino estão entre as organizações que carecem de mudanças gerenciais inovadoras, sobretudo no setor público, induzidas pelo ambiente em que estão inseridas e pelas rápidas transformações advindas das tecnologias da informação e comunicação em desenvolvimento e seus complexos sistemas, rompendo o paradigma da biblioteca taylorista.

A tendência é que as organizações se adaptem continuamente às novas situações se desejam sobreviver e prosperar, tornando-se organizações aprendentes (ZACCARO, 2003). E a biblioteca, enquanto organização, deverá buscar os caminhos necessários para acompanhar esse processo inovador devido às demandas da sociedade contemporânea.

Dudziak (2003, p. 34) aponta que "os desafios são grandes, e o aprendizado é longo, mas possível". Também afirma que "é preciso repensar o papel do bibliotecário e repensar a biblioteca enquanto organização para que ocorra a expansão da transformação da educação e da implementação de programas educacionais voltados para a competência em informação". Esta encontra-se no âmago do processo de aprendizagem ao longo da vida. Talvez seja com a implementação e gestão de programas e projetos educacionais voltados para a competência em informação que seja possível transformar a biblioteca em uma organização aprendente. Mas este é apenas um indício que se apresenta nesta trama intelectual e investigativa.

As bibliotecas são cada vez mais desafiadas a transformarem-se em agentes de mudanças no âmbito de sua atuação, não se limitando aos papéis de repositórios de informações e prestadora de serviços, mas são chamadas a adotarem práticas de inovação organizacional que as tornem organizações aprendentes .

Fornecer suporte informacional, complementar às atividades curriculares dos cursos, e oferecer recursos para facilitar estudos e pesquisa consiste na finalidade das bibliotecas nas instituições de ensino. Sua missão é prover informação para o ensino, a pesquisa e a extensão de acordo com a política, o projeto pedagógico e os programas da instituição na qual está inserida. Corrobora-se com Dudziak (2004) ao afirmar que são fatores que compromete a evolução organizacional das bibliotecas, os seguintes: a pouca tradição, a carência de recursos materiais, o despreparo no que tange ao ensino e à pesquisa, a escassez de recursos humanos qualificados, os orçamentos limitados e desvinculados do planejamento educacional da instituição, incluindo a ausência do planejamento bibliotecário.

Conforme apregoam Benine e Pinheiro (2010, p. 83, grifo nosso), o conceito de organização:

compreende a ideia de um conjunto de recursos estruturados com a função de alcançar metas e realizar os objetivos propostos. A universidade, a prefeitura, a biblioteca, o teatro, o shopping center, a lanchonete da escola, o centro acadêmico, entre outros, são exemplos de organização.

Organizações diferenciam-se em diversos fatores, incluindo diversidade de tamanho, forma, produtos, serviços, tecnologias, recursos, pessoas, áreas de atuação, complexidade gerencial, filosofia, missão, etc. Cada organização possui sua própria cultura organizacional. Corroborando com Benine e Pinheiro (2010, p. 83), isso 
inclui a maneira como o indivíduo aprende, dentro da organização, a lidar com seu ambiente de trabalho e a conviver nesse ambiente. Trata-se, portanto, de uma complexa mistura de pressuposições, crenças, comportamentos, histórias, mitos, metáforas e outras ideias que juntas representam o modo particular de uma organização funcionar (CHIAVENATO, 1999, p. 140). Por estas razões é fundamental que as bibliotecas, enquanto organizações, considerem a relevância das narrativas orais e das percepções que seus usuários e colaboradores possuem dela própria, a partir de uma autorreflexão crítica frequente de seu clima e de sua cultura, seja por estudo de usuários, pesquisas aplicadas, observação participante, ou qualquer outro método necessário para coletar informações sobre sua imagem organizacional no contexto social na qual encontra-se inserida e atuante.

Entre os vários elementos constituintes da cultura organizacional, destacamse: o cotidiano do comportamento observável (relacionamentos interpessoais, interações, expressões, gestos e rotinas); as regras/normas comportamentais dos grupos verificáveis; e a filosofia administrativa que orienta o funcionamento das políticas da organização em relação aos colaboradores internos e externos envolvidos (BENINE; PINHEIRO, 2010, p. 91). São elementos, portanto, que requerem atenção por parte dos gestores comprometidos com a inovação, a excelência e a melhoria contínua das organizações em que atuam.

O profissional da informação bibliotecário é o agente responsável pela coordenação dos trabalhos de organização, arquitetura, disponibilização, busca, recuperação e disseminação da informação disponíveis nas bibliotecas das instituições de ensino. Compete ao bibliotecário gestor pensar sobre a complexidade gerencial da organização em que atua, incluindo a gestão de pessoas. Para alcançar os objetivos da gestão de pessoas é importante que os bibliotecários gestores, no desempenho de suas funções clássicas - planejar, organizar, dirigir e controlar incentivem a colaboração, por meio da motivação e ensinamento administrativo dos demais membros da equipe de trabalho. É necessário que haja uma atuação gerencial que possibilite a ênfase nos focos de aprendizagem da organização, gerando subsídios ao desenvolvimento criativo da(s) equipe(s) e sua participação efetiva nas tomadas de decisão. A participação das pessoas no processo decisório institucional aumenta as chances das organizações conseguirem atingir seus objetivos e metas com excelência (PINTO; GONZÁLEZ, 2010). Tomando por referencial Angeloni (2002), compreende-se que o objetivo de trabalhar a aprendizagem nas organizações é desenvolver nos integrantes a capacidade de aprender continuamente com vistas ao estabelecimento da vantagem competitiva organizacional.

Conforme apregoado por Silva (2009, p. 97), "tanto as organizações aprendem com as pessoas, como as pessoas aprendem com o conhecimento institucionalizado nas organizações". Há que ocorrer, portanto, uma mudança de foco da competição para a competência, em que se enalteça o trabalho em equipe, o compartilhamento de informações e a aprendizagem organizacional. Este é um desafio que se apresenta também para as bibliotecas neste século XXI.

As bibliotecas foram por anos concebidas como meros repositórios de livros ou depósitos de informação. Há poucas décadas a perspectiva vem mudando, e o conceito de biblioteca ampliando-se para além da armazenagem, dando-se ênfase cada vez maior aos serviços diversificados de informação e, em especial, à educação de usuários. Ao compararmos a educação tradicional com a educação voltada para as competências em informação, corrobora-se com Dudziak (2001, p. 73) quando apregoa a ideia de que no contexto da educação voltada para as competências em informação "as bibliotecas são vistas como sistemas aprendentes, centros de aprendizado, ambientes multiculturais." Dudziak (2001, p. 73), em referência ao processo de transformação da biblioteca em uma organização aprendente, apregoa que "as bibliotecas enfrentam o desafio de se transformarem de mero repositório de 
informações, em agentes provocadores de mudanças educacionais. Para se constituírem em organizações e espaços aprendentes, têm de buscar sua própria evolução". Não é o bastante dar nomes novos a velhas práticas, sendo necessário, portanto, que haja a busca por uma identidade nova a partir de um longo e intenso processo de reflexão, aprendizagem, transparência de processos, investigações científicas, baseando-se no desenvolvimento de competências em informação para construção da imagem da biblioteca como organização aprendente no ambiente escolar e universitário.

O espírito de trabalho colaborativo entre administradores, bibliotecários, docentes e técnicos é uma das premissas para que se desenvolvam programas e projetos educacionais voltados para o desenvolvimento de competências em informação. Esse trabalho em equipe depende do modo como bibliotecários se relacionam com a comunidade e como veem a si mesmos inseridos no contexto educacional. Corroborando com Dudziak (2001), a biblioteca aprendente consiste em um espaço de expressão e aprendizado.

A compreensão do que e como as pessoas aprendem, seja no nível individual ou de grupo, requer estudo do modelo de gestão organizacional atual e pretendido para o futuro, de acordo com as demandas e expectativas dos profissionais que atuam neste grupo. Silva (2009) afirma que a aprendizagem apresenta-se como um fenômeno complexo, que demanda um processo de reflexão sobre a prática gerencial, sobretudo na contemporaneidade e no contexto das bibliotecas.

A aprendizagem permite que a organização e as pessoas se acostumem a lidar com mudanças (ZACCARO, 2003). Partindo desta concepção, percebemos que a inovação gerencial em bibliotecas abrange a implementação da cultura da aprendizagem organizacional. A biblioteca pode se tornar organização aprendente, mas não a partir de uma receita pronta ou um modelo de aplicação genérica. Entre os vários percursos possíveis, há que se compreender que a aprendizagem organizacional é cíclica, abrangendo os seguintes passos: visão compartilhada, pensamento sistêmico, modelos mentais, excelência pessoal e aprendizagem em equipe (ZACARRO, 2003). Senge (1997, p. 22) diz que "grandes equipes são organizações aprendentes - grupos de pessoas as quais, continuamente desenvolvem a capacidade de criar aquilo que elas verdadeiramente desejam criar". $\mathrm{E}$ as competências são nesta pesquisa compreendidas como a mobilização dos saberes (saber, saber agir e saber ser) requeridos pelo contexto da ação (LE BOTERF, 2003; MOURA e BITENCOURT, 2006). Uma nova concepção de profissionais capazes de lidar com as incertezas presentes no mundo do trabalho é exigida na atualidade. 0 enfoque para as competências se constitui em uma alternativa promissora às constantes transições presentes neste contexto.

Dudziak (2001) reafirma o papel da biblioteca aprendente, relacionando-a diretamente às competências em informação, de forma indissociável, ao dizer que esta

deve focalizar seus esforços na formação de pessoas, cidadãos que sejam capazes de pensar criticamente, aprender de maneira independente (aprender a aprender), capacitadas a buscar, [acessar] e usar a informação no seu dia a dia, na resolução de problemas ou realização de projetos, tarefas, ou simplesmente em função de uma curiosidade pessoal, de forma a incutir-lhes o gosto pelo aprendizado ao longo da vida. Esta é a própria tradução da expressão Information Literacy.

A biblioteca pode e deve ser percebida e reconhecida como uma organização aprendente ao constituir-se em um ambiente favorável à aprendizagem e ao desenvolvimento de competências em informação. E, corroborando com Silva (2009), há que se evidenciar que o processo de aprendizagem está intimamente 
vinculado à construção de um processo de renovação de valores, atitudes e conduta profissional.

Conforme apregoado por Dudziak (2001, p. 92) "a chave para um novo conceito de biblioteca, mais adequado ao momento atual e consonante com as [Competências em Informação], é sua transformação de organização taylorista em organização aprendente". Essa citação de Dudziak nos revela que na sociedade contemporânea um novo conceito de biblioteca, quiçá "biblioteca aprendente", é necessário e requer foco nas competências em informação.

\section{COMPETÊNCIAS EM INFORMAÇÃO NA SOCIEDADE APRENDENTE}

Oriunda de um cenário que fez emergir a cibercultura, em meio aos avanços das telecomunicações e da informática, a Sociedade da Informação, cujo termo surgiu em 1970, especialmente nos EUA e Japão, caracteriza-se pela organização das atividades humanas a partir do uso das tecnologias de informação e comunicação. Conforme apregoado por Freire (2007, p.39-40), a Sociedade da Informação caracteriza-se pela velocidade de transmissão da informação e da criação e renovação de conhecimentos, pelo uso intensivo da informação, pela natureza do trabalho cada vez mais ligado ao conhecimento e pelo surgimento do ciberespaço, que possibilita a circulação de um número incalculável de informações e amplia a influência das tecnologias intelectuais sobre as funções cognitivas humanas.

Assman (2000) apregoa a importância de considerar a sociedade da informação como uma sociedade da aprendizagem ou sociedade aprendente. E destaca a relevância das políticas públicas no acesso à sociedade da informação. $\mathrm{Na}$ sociedade brasileira, um exemplo recente, de aprimoramento da gestão pública e das políticas públicas, relevante para a consolidação da Sociedade da Informação no Brasil, é a criação da lei no 12.527 , de 18 de novembro de 2011, conhecida como Lei de Acesso à Informação, que regulamenta o direito constitucional de acesso às informações públicas e possibilita que os cidadãos participem mais ativamente da gestão pública. Constitui-se, portanto, em um importante instrumento que contribui de maneira qualificada para a construção de um debate coletivo frente às novas possibilidades de gerir os recursos públicos.

No âmago de uma dinâmica complexidade social, em que a informação globalizada e em rede possibilita a formação de uma sociedade do aprendizado contínuo, a tendência é que as organizações se adaptem continuamente às novas situações se desejam sobreviver e prosperar, tornando-se, portanto, organizações que aprendem (learning organizations) (ZACCARO, 2003). Garvin (2001, p. 83) apregoa que as organizações aprendentes "estão capacitadas a criar, a adquirir e a transferir conhecimentos e, ainda, a modificar seus comportamentos para refletir esses novos conhecimentos e insights". Desta forma, as organizações aprendentes estariam mais próximas do perfil desejado na dinâmica das relações sociais no contexto da Sociedade da Informação (Sociedade Aprendente).

Uma nova concepção de profissionais capazes de lidar com as incertezas presentes no mundo do trabalho é exigida na contemporaneidade. 0 enfoque para as competências gerenciais é uma alternativa promissora às constantes transições presentes neste contexto. No mundo do trabalho globalizado, da sociedade da informação, é preciso, também, desenvolver continuamente as competências em informação.

O conhecimento está em rede e a sociedade contemporânea está alicerçada no aprendizado contínuo e no poder da informação (CASTELLS, 2003). As organizações sejam elas públicas ou privadas, de pequeno, médio ou grande porte, são constituídas por pessoas, e tornam-se aprendentes, na medida em que as pessoas aprendem. As organizações aprendentes na Sociedade da Informação conseguem promover mais inovação e são capazes de promover transformação 
social com inclusão, pois somam as competências individuais com a capacidade de aprender, resultando em uma inteligência coletiva capaz de responder a toda e qualquer mudança do meio interno e externo, algo típico nas sociedades globalizadas e sem fronteiras.

Na Sociedade da Informação, os ambientes de aprendizagem vão do real ao virtual, do local ao global. A escola deixa de ser o ambiente exclusivo para construção do conhecimento. Um novo mundo do trabalho estar a constituir-se, potencializado pelos incomensuráveis recursos da Internet. A interatividade e o digital permeiam a grande maioria das atividades laborais humanas. As organizações aprendentes, neste contexto, apresentam-se, portanto, como uma perspectiva de gestão sustentável e apropriada para as exigências contemporâneas do mercado profissional e dos novos modos de (con)viver.

Serafim (2011, p. 35) apregoa que a concretização de uma Sociedade Aprendente dependerá fortemente da função educacional dos profissionais da informação, especialmente dos bibliotecários. A tradicional preocupação desses profissionais com os usuários das bibliotecas amplia-se para a necessária capacitação dos indivíduos contemporâneos no emergente cenário informacional que se delineia. Tais habilidades são compreendidas como competências em informação.

A literatura científica comprova que há décadas as bibliotecas têm realizado estudos de usuários, para identificarem e conhecerem seu público, e assim poderem melhor atender suas demandas informacionais. Na trajetória histórico-evolutiva das práticas biblioteconômicas, nota-se que os treinamentos de usuários de biblioteca, com a finalidade de orientá-los quanto ao melhor uso da biblioteca, foram realizados até meados dos anos 80 , evoluindo, posteriormente, para o conceito de educação de usuários, que é concebido, na atualidade, como a semente das competências em informação.

Utilizada a partir dos anos 70, a expressão "educação de usuários", foi definida por Fleming (1990, p. 9) como "vários programas de instrução, educação e exploração oferecidos pelas bibliotecas aos seus usuários para capacitá-los a fazer um uso mais eficaz, eficiente e independente das fontes, recursos e serviços de informação que estas bibliotecas oferecem". Entretanto, na atualidade, um novo termo emergiu com o advento da Sociedade da Informação, para definir a evolução do serviço educacional realizado pelos bibliotecários: desenvolvimento de competências em informação. Além de denotar amplitude conceitual, o novo termo é mais atraente e coeso com o fenômeno da Sociedade da Informação, advindo do final do século XX.

Numa visão mais contemporânea da educação de usuários, corroborando com Serafim (2011), temos que:

"como evolução da educação de usuários de bibliotecas, a educação em competências em informação constitui-se numa perspectiva moderna de aprendizagem que busca capacitar os indivíduos para lidar com desafios informacionais em diferentes áreas da vida humana. Dentre elas, habilidades de avaliar a credibilidade, exatidão, atualidade e aplicabilidade das informações, assim como habilidades tecnológicas para busca e recuperação de informação."

O termo "competências em informação" é originariamente norte-americano e apresenta-se na língua portuguesa como tradução do termo "information literacy". Foi idealizado pelo advogado Paul Zurkowski, em 1974, enquanto presidente da Information Industry Association, em um relatório para a National Commission on Libraries and Information Science, intitulado "The Information Service Environment Relationships and Priorities - Related Paper No 5". 
Conforme o conceito de informação, as competências em informação só podem ser analisadas a partir das práticas sociais institucionalizadas (SERAFIM, 2011). "Informação é social" e "[...] todas as habilidades informacionais dependem fortemente de um entendimento claro do contexto no qual um indivíduo atua" (HOYER, 2011). Da mesma forma que para desenvolver projetos que visem ao desenvolvimento de competências em informação, é preciso conhecer o comportamento informacional de seus usuários.

Segundo Stewart (2011, p. 270), as competências em informação serviram também como um modo das bibliotecas acadêmicas justificarem o valor de suas atividades diante da crescente frustração do Ensino Superior: formar profissionais, com habilidades de pensamento crítico e de aprendizado para toda vida.

Derakhshan e Singh (2011), apregoam que a eliminação do mito que as competências em informação não se constituem num esforço único da biblioteca e que os bibliotecários não podem contribuir nas atividades de ensino-aprendizagem é fundamental neste processo.

Burke (2010) identifica como grupos com influência no desenvolvimento de tais habilidades informacionais, os seguintes:

Especialistas em bibliotecas devem atuar como líderes na modelagem, ensino e promoção de habilidades em competências em informação. Os pais podem promover e influenciar o ensino de habilidades em competências em informação ao aplicar habilidades de competências em informação com seus filhos em casa, e defender a necessidade de mais instruções nesta área para professores, administradores e políticos. Professores podem influenciar as competências em informação ao ensinar.

Serafim (2011) diz que o uso da informação (de modo eficiente, ético, criativo e crítico) é reconhecidamente um fator-chave para o sucesso na academia, justificando o desenvolvimento de competências em informação entre os acadêmicos.

Uma das definições mais citadas na literatura da área de Ciência da Informação, corroborando com Dudziak (2003, p. 26), sobre as competências em informação, é da ALA, American Library Association, (1989, p.1), que apregoa que:

"Para ser competente em informação, uma pessoa deve ser capaz de reconhecer quando uma informação é necessária e deve ter a habilidade de localizar, avaliar e usar efetivamente a informação... Resumindo, as pessoas competentes em informação são aquelas que aprenderam a aprender. Elas sabem como aprender, pois sabem como o conhecimento é organizado, como encontrar a informação e como usá-la de modo que outras pessoas aprendam a partir dela."

Essa definição, relaciona-se intimamente com os princípios que explicam as organizações aprendentes, e contribui para legitimar teoricamente que tais organizações aprendentes constituem-se espaços de desenvolvimento de competências em informação. Afinal, conforme apregoado por Belluzzo, Santos e Almeida Júnior (2014, p. 102),

o desenvolvimento de competência em informação, requer um tratamento que envolve desde a compreensão da informação em seu sentido mais amplo e as exigências das sociedades humanas, dependendo fundamentalmente da educação, recomendando-se que haja um trabalho integrado entre educadores e bibliotecários.

A pesquisa-ação buscou meios para investigar e compreender a relação prática dos conceitos até então estudados e apresentados. 


\section{PESQUISA-AÇÃO PARA O DESENVOLVIMENTO DO PROJETO EDUCATIVO}

Produzir um projeto educativo de desenvolvimento de competências em informação para uma das bibliotecas do Instituto Federal de Educação, Ciência e Tecnologia da Paraíba (IFPB) foi um dos objetivos da pesquisa-ação realizada em nível de mestrado que buscou dar início a um complexo estudo sobre o desenvolvimento de competências em informação em biblioteca multinível.

Corroborando com Minayo (2010, p. 23) a pesquisa científica é "uma atividade de aproximação sucessiva da realidade que nunca se esgota, fazendo uma combinação particular entre teoria e dados". Metodologia nada mais é do que o caminho percorrido pelo pesquisador a fim de atender os objetivos da pesquisa, alinhado ao referencial teórico adotado. Ainda de acordo com Minayo (2009, p.22) "a metodologia inclui as concepções teóricas de abordagem, o conjunto de técnicas que possibilitam a apreensão da realidade e também o potencial criativo do pesquisador". A escolha da metodologia leva em consideração, portanto, a mais adequada para compreensão do fenômeno estudado. Entende-se como metodologia adequada aquela que viabiliza a trilha investigativa objetivada, incluindo as bases teóricas fundamentais, sem restringir a criatividade científica e sem se distanciar da realidade estudada.

A linha de pesquisa em que esta pesquisa esteve inserida, no contexto do Programa de Pós-Graduação em Gestão nas Organizações Aprendentes, intitula-se "Gestão de Projetos Educativos e Tecnologias Emergentes", o que contribuiu para a escolha metodológica, das técnicas e dos procedimentos para a pesquisa realizada. No entanto é imprescindível também dizer que é a questão de pesquisa que domina a seleção do método e não o contrário (JARVINEN, 2004, p. 3). Por isto levou-se em consideração a questão norteadora desta investigação para a escolha do método indutivo. A questão de pesquisa escolhida foi: Qual a relação existente entre um projeto educativo de desenvolvimento de competências em informação e o processo de transformação da biblioteca convencional em uma organização aprendente?

Com incipiente conhecimento teórico e conceitual sobre o processo de transformação da biblioteca em uma organização aprendente, e almejando-se não apenas a compreensão do objeto de estudo, mas também a construção de novos conhecimentos, sob uma perspectiva interdisciplinar, deve-se optar por uma abordagem de natureza qualitativa, por ser mais promissora neste tipo de investigação. 0 crescimento e a relevância das pesquisas qualitativas nas Ciências Humanas e Sociais Aplicadas comprovam sua consolidação em diversas disciplinas e múltiplos contextos (ANGROSINO, 2009). Esse tipo de abordagem adequa-se mais para a compreensão e explicação de fenômenos sociais. Conforme citação apresentada no início deste capítulo, de autoria de Kurt Lewin, criador do termo "Action Research", conforme dito por Lima (2007, p. 63), a pesquisa deve produzir mais coisas além de livros, algo cabível e que foi possível realizar nesta pesquisa, alinhando-se aos propósitos do Mestrado Profissional.

Esse tipo de estudo deve ser percebido como uma pesquisa de natureza qualitativa, fundamentada em uma metodologia de pesquisa-ação, na qual as técnicas e os instrumentos utilizados se diferenciam durante a evolução do estudo para cumprir os objetivos específicos propostos, valorizando, assim, a força da autonomia do processo investigado.

A pesquisa-ação tem por finalidade servir de instrumento para mudança social (BARBIER, 2007, p. 53). Caracteriza-se, segundo Tripp (2005, p.443) por ser "uma forma de investigação-ação que utiliza técnicas de pesquisa consagradas para informar a ação que se decide tomar para melhorar a prática". Segundo Thiollent (2007, p.15) a pesquisa-ação permite que o investigador exerça "um papel ativo no equacionamento dos problemas, no acompanhamento e na avaliação das ações desencadeadas em função dos problemas". 
Trata-se de um tipo de pesquisa

com base empírica que é concebida e realizada em estreita associação com uma ação ou com a resolução de um problema coletivo e no qual os pesquisadores e os participantes representativos da situação ou do problema estão envolvidos de modo cooperativo ou participativo (THIOLLENT, 2007, p.14).

Segundo Pereira (2009), a característica mais marcante da pesquisa-ação consiste nela se modificar continuamente em espirais de reflexão e ação, e que, ao invés de se limitar ao uso de um saber existente (característico da pesquisa aplicada), busca mudanças no contexto concreto e estuda as condições e os resultados da experiência efetuada. Um dos benefícios da escolha desta metodologia está na possibilidade de provocar mudanças e melhorias no ambiente organizacional. Afinal, conforme apregoado por Barbier (2007, p. 45), "a pesquisaação visa sempre mudança", sendo a pesquisa-ação uma forma de pesquisa na qual há uma ação deliberada de transformação da realidade, possuindo um duplo objetivo: transformar a realidade e produzir conhecimentos relativos a essas transformações.

A pesquisa-ação caracteriza-se pelo desencadeamento de ações e reflexões acerca das ações realizadas. 0 contexto organizacional, seus atores e o processo devem ser analisados com a isenção do pesquisador, ainda que ele também se constitua num dado da pesquisa. Ao contrário da pesquisa social convencional, a pesquisa-ação não se restringe apenas à análise dos aspectos individuais manifestados como opiniões, atitudes, motivações, mas busca observar e compreender a dinâmica dos problemas, decisões, ações, negociações, conflitos e tomada de decisões entre os agentes do processo de transformação da situação (SCAPECHI,2007). No caso da investigação realizada, consistiu em um primeiro e grande momento de uma pesquisa que se propõe maior enquanto pesquisa-ação. Este estudo, portanto, não pretende ser um estudo conclusivo e acabado, pois o processo de pesquisa-ação é cíclico e deverá continuar para além da investigação realizada e aqui apresentada, buscando responder outras questões necessárias a compreensão do processo de transformação da biblioteca em uma organização aprendente, em especial, da importância da gestão de um projeto educativo para o desenvolvimento de competências em informação, ou porque não um programa de competências em informação envolvendo e articulando projetos diversos para usuários também diversos no espaço da biblioteca multinível.

No processo de investigação-ação, aprende-se mais "tanto a respeito da prática quanto da própria investigação" (TRIPP, 2005, p. 446). Na Figura 1, é possível observar a validação desta premissa a partir da compreensão do ciclo da investigação-ação, que consiste nas etapas de planejamento, implementação, descrição e avaliação. No estudo realizado deu-se ênfase no planejamento e na implementação a partir dos dados coletados por pesquisa documental e bibliográfica, aliada a técnica da observação participante e de organização e articulação de categorias, pois a ação não pode ser desvinculada da pesquisa neste tipo de investigação. Destaca-se, neste tipo de pesquisa, a necessidade de monitorar e avaliar os efeitos e resultados da ação, possibilitando revelar as possibilidades e limitações do processo em relação ao regime de informação. Essa opção metodológica é natural em uma pesquisa-ação e própria do fenômeno estudado.

De acordo com Lima (2007, p.68), "uma das principais características da Pesquisa-Ação é a repetição das suas etapas em um processo cíclico que transita ora no domínio da pesquisa, ora no domínio da ação". Corroborando com Engel (2000, p. 184), percebemos que a Pesquisa-Ação pode ser também classificada como autoavaliativa e situacional, afinal, ela procura diagnosticar um problema específico numa situação também específica, com a finalidade de atingir uma relevância prática 
dos resultados, constituindo-se em um processo de aprendizagem para todos os sujeitos participantes nela envolvidos, incluindo a aprendizagem organizacional. Esta premissa reforça ainda mais a justificativa de escolha desta metodologia para realização do estudo proposto.

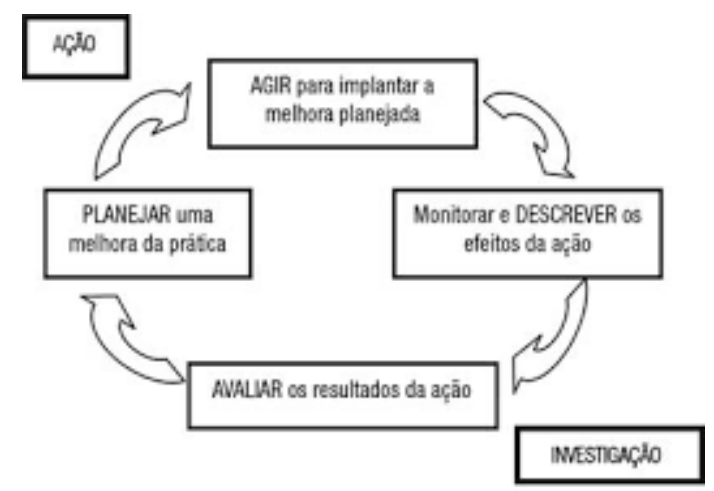

Figura 1: Representação esquemática do ciclo da Investigação-Ação de David Tripp Fonte: TRIPP (2005, p. 446).

Ao mesmo tempo em que a pesquisa-ação se propõe a solucionar problemas práticos, ela se fundamenta teórico-conceitualmente ao longo de toda sua trajetória de planejamento e execução.

Para atender a proposta de intervenção, desenvolvimento e mudança no âmbito organizacional a que esse estudo se propõe, a pesquisa-ação deve apresentar uma fase descritiva e outra exploratória, privilegiando o contato direto com o campo em que está sendo desenvolvida e implicando o reconhecimento visual do local, a consulta a documentos diversos e sobretudo a investigação dos sujeitos sociais e da organização envolvidos com os objetivos da pesquisa (GIL, 2010, p. 152).

Tal abordagem metodológica escolhida oportuniza de um lado resultados práticos alcançados pela resolução inovadora de um problema, e, do outro, a contribuição para a literatura científica em termos de resultados de pesquisa. Conforme apregoado por Lima (2007, p.64), corroborando com McKay e Marshall (2001, p.42), o compromisso da pesquisa-ação com a produção de novo conhecimento ocorre a partir da procura por solução ou melhorias de problemas práticos da vida real. É o que ocorreu na pesquisa de Mestrado que originou esse trabalho. A ênfase, naquele momento, foi a identificação do problema e o planejamento de uma solução respaldada em uma rede conceitual de articulação de categorias, que possibilitou a projeção de um projeto educativo para o desenvolvimento de competências em informação no âmbito de uma biblioteca com características diferentes dos tipos já existentes, a saber: bibliotecas escolares, universitárias, especializadas, infantil, nacional e especial.

0 ponto de partida da pesquisa que originou esse trabalho foi a literatura científica na perspectiva interdisciplinar das Ciências Sociais Aplicadas e da Educação, universo o qual está situado o Programa de Pós-Graduação em Gestão nas Organizações Aprendentes. Tal literatura científica possibilita estabelecer estas bases teórico-conceituais apresentadas neste trabalho, oportunizando compreender a relação entre organização aprendente, competências em informação, projeto educativo e bibliotecas.

A partir disto, delimitou-se como universo da pesquisa o Instituto Federal de Educação, Ciência e Tecnologia da Paraíba, Campus Sousa, por esta ser uma instituição que faz parte da Rede Federal EPCT e por ser o espaço de atuação profissional do pesquisador, permitindo exercer o propósito da pesquisa-ação. Mais especificamente, a biblioteca do IFPB Campus Sousa consistiu em unidade de análise para atender os objetivos da pesquisa. Através de descrição do perfil e do espaço de 
atuação desta, foi possível executar os procedimentos metodológicos adotados que possibilitaram atingir os resultados da pesquisa.

Na fase descritiva, recomenda-se a descrição da Rede Federal de Educação Profissional, Científica e Tecnológica (Rede Federal EPCT) e dos Institutos Federais que dela fazem parte, para compreender o tipo de biblioteca que existe nesse ambiente organizacional, quanto ao perfil, ao espaço de atuação e a sua finalidade. Para tal, pode-se utilizar a pesquisa documental. A observação participante contribui para complementar os dados coletados nos documentos analisados, aproximando ainda mais a pesquisa da realidade organizacional. Podem ser consultados diversos atores envolvidos neste processo por correio eletrônico com a finalidade de realizar levantamento de documentos e informações sobre a instituição, necessárias a descrição, levando em consideração o quantitativo de servidores por cargo na instituição, de discentes e de docentes, e o conteúdo dos Projetos Político-Pedagógicos dos Cursos Técnicos e Superiores. Para fins de descrição e compreensão da Rede Federal EPCT recomenda-se consultar a Lei $n^{0}$ 11.892, de 29 de dezembro de 2008, que instituiu e criou os Institutos Federais de Educação, Ciência e Tecnologia no Brasil.

$\mathrm{Na}$ fase exploratória tem-se a finalidade de descobrir o que está acontecendo, sendo especialmente útil por não se saber o suficiente sobre o fenômeno (GRAY, 2012, p. 36). Gonsalves $(2007$, p. 67) afirma que a pesquisa exploratória caracteriza-se "pelo desenvolvimento e esclarecimento de ideias, com o objetivo de oferecer uma visão panorâmica, uma primeira aproximação a um determinado fenômeno que é pouco explorado". A pesquisa exploratória, neste caso, contribui para o alcance de novas abordagens e perspectivas do objeto de estudo. A relação entre um projeto educativo para usuários da biblioteca no fomento a esta cultura organizacional aprendente certamente é um tema pertinente e relevante, mas até então pouco explorado e conhecido nas literaturas das áreas de Ciência da Informação, Educação e Administração, que compõem a natureza interdisciplinar do Programa de Pós-Graduação em Gestão nas Organizações Aprendentes.

A pesquisa exploratória, neste caso, faz-se relevante e viável, afinal a revisão bibliográfica revela que há temas não pesquisados e ideias vagamente relacionadas com o problema do estudo. A observação participante também pode se fazer presente como recurso metodológico, pois o acesso do pesquisador aos bibliotecários da Rede Federal de Educação Profissional, Científica e Tecnológica por meio de lista de discussão por e-mail permite conhecer mais sobre a realidade das bibliotecas neste contexto em relação ao propósito do estudo. 0 website da Comissão Brasileira de Bibliotecas das Instituições da Rede Federal de Educação Profissional, Científica e Tecnológica no Brasil também pode ser fonte de pesquisa documental para fins de investigação exploratória.

Os dados coletados e analisados culminam na produção de um projeto educativo, realizado por meio de rede conceitual de articulação e organização de categorias. Consiste, portanto, em processo essencialmente indutivo, em que as categorias ou tipologias vão sendo criadas a partir da pesquisa documental e da pesquisa bibliográfica realizada, que juntas permitem a referida criação de uma rede conceitual de organização e articulação de categorias. Para a determinação dessas categorias devem ser utilizados os critérios de Guba e Lincoln (1981), a saber: homogeneidade interna, homogeneidade externa, inclusividade, coerência e plausibilidade. As categorias devem refletir, portanto, os propósitos da pesquisa, o que é recomendável por Guba e Lincoln (1981) e por Lüdke e André (1986), e devem ser elaboradas de acordo com as relações teóricas e conceituais estabelecidas a partir da base teórica, da análise documental, reflexão crítica e observação da realidade organizacional. Este procedimento vai sendo construído durante a própria evolução da pesquisa, condição esta também recomendada por Lüdke e André (1986). Tal procedimento metodológico, portanto, possibilita a sistematização do 
procedimento de investigação, que culmina na produção do projeto educativo para desenvolvimento de competências em informação.

\title{
5 CONSIDERAÇÕES FINAIS
}

0 processo de transformação da biblioteca como organização aprendente é um longo caminho e não se pode prever o seu fim. Diferentemente desta pesquisa que objetivou relacionar o projeto educativo de desenvolvimento de competências em informação com este supracitado processo, a biblioteca aprendente não é um projeto com início, meio e fim. Trata-se de uma filosofia organizacional, que envolve valores e culturas organizacionais, desafia a ciência e, portanto, deve continuar a ser estudada pelos pesquisadores, em conjunto com os bibliotecários, pois a pesquisaação mostra-se como um caminho metodológico viável para ambos: ciência e organização. Ambos podem se beneficiar ainda mais, se caminharem juntos.

Como contribuição, a pesquisa de Mestrado trouxe muito mais que a evidenciação desta relação teórica, trouxe um instrumento de aplicação prática, que neste caso é o próprio projeto educativo, que almeja ser o pontapé inicial para todo aquele bibliotecário que deseje iniciar o processo de transformação da biblioteca em uma organização aprendente a partir do desenvolvimento de competências em informação. Neste trabalho a contribuição é orientar, do ponto de vista metodológico, outras bibliotecas e bibliotecários que se identificam com esta identidade de biblioteca multinível, proposta e idealizada por Moutinho (2014), a proceder da elaboração de seus próprios projetos educativos orientados ao desenvolvimento de competências em informação.

0 mais importante neste momento é perceber a viabilidade do processo, os instrumentos e os caminhos possíveis a serem trilhados. A pesquisa, a partir dos resultados apresentados, aponta para um novo marco nos serviços de informação, conhecimento e aprendizagem da biblioteca multinível.

Conclui que a constituição do projeto educativo contribui no processo de transformação da biblioteca convencional em uma biblioteca aprendente e que a aplicação do projeto educativo, seu monitoramento e sua avaliação podem revelar as possibilidades e limitações do processo em relação ao regime de informação.

Propõe-se que sejam realizados estudos futuros, a partir deste realizado, em que seja evidenciada a percepção e atuação dos demais bibliotecários da Rede Federal de Educação Profissional neste contexto. Os resultados apresentados nesta pesquisa são um ponto de partida rumo a biblioteca aprendente. 0 caminho já está sendo percorrido, é preciso seguir em frente.

\section{REFERÊNCIAS}

\author{
AMERICAN LIBRARY ASSOCIATION. Report of the Presidential Committee on \\ information literacy: Final Report. [S. 1.], 1989. Disponível em: \\ <http://www.ala.org/acrl/publications/whitepapers/presidential>. Acesso em: ago. 2000.
}

ANGELONI, M.T (Coord.). Organizações do conhecimento: infra-estrutura, pessoas, tecnologia. São Paulo: Saraiva, 2002.

ANGROSINO, M. Etnografia e observação participante. Porto Alegre: Artmed, 2009.

BARBIER, R. A. Pesquisa-Ação. Brasília: Liber, 2007. Tradução de Lucie Didio.

BELLUZZO, Regina C. B; SANTOS, Camila A. dos; ALMEIDA JÚNIOR, Oswaldo F. de. A competência em informação e sua avaliação sob a ótica da mediação da informação: reflexões e aproximações teóricas. Inf. Inf., Londrina, v. 19, n. 2, p. 60-77, maio/ago. 2014. Disponível em: < 
https://www.marilia.unesp.br/\#!/Home/Graduacao/PETBiblioteconomia/a-competenciaem-informacao.pdf >. Acesso em 08 ago. 2015.

BENINE, Fabiana; PINHEIRO, Renata James Diógenes. Cultura da organização: conceitos. In: BERAQUET, Vera Silva Marão; CIOL, Renata (orgs.). 0 profissional da informação na gestão: uma coletânea. Campinas: Akademika, 2010.

BRASIL. Lei no 11.892 de 29 de dezembro de 2008. Institui a Rede Federal de Educação Profissional, Científica e Tecnológica, cria os Institutos Federais de Educação, Ciência e Tecnologia, e dá outras providências. Diário Oficial [da] República Federativa do Brasil, Brasília, DF, 30 dez. 2008. Disponível em: < http://pesquisa.in.gov.br/imprensa/jsp/visualiza/index.jsp?jornal=1\&pagina=1\&data=30/1 2/2008>. Acesso em 01 out. 2015.

BURKE, Melynda. Overcoming challenges of the technological age by teaching information literacy skills. Community \& Junior College Libraries, v. 16, p. 247-254, 2010.

CASTELLS, Manuel. A Galáxia da Internet: reflexões sobre a internet, os negócios e a sociedade. Rio de Janeiro: Jorge Zahar, 2003.

CHIAVENATO, Idalberto. Gestão de pessoas: o novo papel dos recursos humanos nas organizações. Rio de Janeiro: Campos, 1999.

DERAKHSHAN, Maryam; SINGH, Diljit. Integration of information literacy into the curriculum: a meta-synthesis. Library Review, v. 60, n. 3, p. 218-229, 2011.

DUDZIAK, E. A. A information literacy e o papel educacional das bibliotecas. 2001. Dissertação (Mestrado) - ECA-USP. São Paulo, 2001.

DUDZIAK, E. A. Information literacy: princípios, filosofia e prática. Ci. Inf., Brasília/DF, v. 32, n. 1, jan./abr. 2003.

DUDZIAK, Elizabeth Adriana. Tendências inovadoras em bibliotecas universitárias: rumo à constituição de Learning Libraries. In: SEMINÁRIO NACIONAL DE BIBLIOTECAS UNIVERSITÁRIAS, 13., 2004, Natal. Anais... Natal: UFRN, 2004.

ENGEL, G. I. Pesquisa-Ação. Revista Educar, n. 16, p. 181-191, 2000.

FLEMING, H. (Ed.) User Education in Academic Libraries. London, The Library Association, 1990.

FREIRE, Gustavo Henrique de Araújo. 0 trabalho de informação na sociedade do aprendizado contínuo. Inf.\&Soc.:Est., João Pessoa, v. 17, n. 3, p. 39-45, set./dez. 2007.

GARVIN, David A. Construindo a organização que aprende. In: Gestão do conhecimento.

Harvard Business Review. Rio de Janeiro: Campus, 2001.

GIL, Antônio Carlos. Como elaborar projetos de pesquisa. 5 ed. São Paulo: Atlas, 2010.

GONSALVES, E. P. Conversas sobre iniciação à pesquisa científica. Campinas: Alínea, 2007.

GRAY, D. E. Pesquisa no mundo real. Porto Alegre: Penso, 2012.

GUBA, E.G.; LINCOLN, Y.S. Effective evaluation. San Francisco: Jossey-Bass, 1981.

HOYER, Jennifer. Information is social: information literacy in context. Reference Services Review, v. 39, n. 1, p. 10-23, 2011.

JARVINEN, P. On Research Methods. Tampereen: Yliopistopaiano Oy. 2004. 203 p.

LE BOTERF, G. Desenvolvendo a competência dos profissionais. 3 ed. Porto Alegre: Artmed, 2003.

LIMA, João Alberto de Oliveira. Pesquisa-ação em Ciência da Informação. In: MUELLER, Suzana Pinheiro Machado. Métodos para a pesquisa em Ciência da Informação. Brasília: Thesaurus, 2007.

LÜDKE, M.; ANDRÉ, M.E.D.A. Pesquisa em educação: abordagens qualitativas. São 
Paulo, EPU, 1986.

MAPONYA, Pearl M. Knowledge management practices in academic libraries: a case study of the University of Natal, Pietermaritzburg Libraries. 2004. Disponível em: < http://www.ukzn.ac.za/department/data/leap_scecsalpaper.pdf/>. Acesso em: 27 set. 2015.

McKAY, J.; MARSHALL, P. The Dual Imperatives of Action Research. Information Technology \& People, v. 14, n. 1, p. 46-59, 2001. Disponível em: < http://www.emeraldinsight.com/doi/full/10.1108/09593840110384771>. Acesso em 10 jul. 2015.

MINAYO, Maria Cecília de Souza. o desafio do conhecimento. São Paulo: Hucitec, 2010.

MINAYO, Maria Cecília de Souza (Org.). Pesquisa social: teoria, método e criatividade. 28. ed. Petrópolis: Vozes, 2009.

MOURA, M. C. C. de; BITENCOURT, C. C. A articulação entre estratégia e o desenvolvimento de competências gerenciais. RAE - eletrônica, v. 5, n. 1, Art. 3, jan./jun. 2006. Disponível em: <http://www.scielo.br/pdf/raeel/v5n1/29560.pdf>. Acesso em: 01 ago. 2013.

MOUTINHO, Sônia Oliveira Matos. Práticas de leitura na cultura digital de alunos do ensino técnico integrado do IFPI- Campus Teresina Zona Sul. 2014. 183 f. Dissertação (Mestrado em Educação) - Universidade Vale do Rio dos Sinos, São Leopoldo, 2014. Disponível em: $<$ http://bdtd.ibict.br/vufind/Record/USIN_5f4c39e1f005401a2a050ba3feaf1a58>. Acesso em: 01 out. 2015.

NISEMBAUM, H. Gestão do conhecimento. In: BOOG, G. (Coord.) Manual de treinamento e desenvolvimento: um guia de operações. São Paulo: Makron Books, 2001.

PEREIRA, E. M. de A. Professor como pesquisador: o enfoque da pesquisa-ação na prática docente. In: SERALDI, C. M. G.; FIORENTINI, D.; PEREIRA, E. M. de A. (Org.). Cartografias do trabalho docente: professor(a)- pesquisador(a). Campinas: Mercado das Letras; ALB, 2009. p. $153-182$.

PINTO, A. L.; GONZÁLEZ, J. A. M. O profissional bibliotecário como gestor de pessoas. In: BERAQUET, Vera Silva Marão; CIOL, Renata (orgs.). 0 profissional da informação na gestão: uma coletânea. Campinas: Akademika, 2010.

SCAPECHI, W. . Projetos educacionais em bibliotecas de instituições de ensino superior: relato de uma experiência.. In: II Seminário em Ciência da Informação, 2007, Londrina. Anais... Londrina: UEL, 2007.

SENGE, P. A quinta disciplina-caderno de campo: estratégias e ferramentas para construir uma organização que aprende. Rio de Janeiro: Qualitymark, 1997.

SERAFIM, Lucas Almeida. Competências em informação na educação superior: um estudo com os professores do curso de Agronomia do Campus UFC Cariri. Dissertação (Mestrado em Ciência da Informação) - Universidade Federal da Paraíba. João Pessoa, 2011.

SILVA, Anielson Barbosa da. Como os gerentes aprendem? São Paulo: Saraiva, 2009.

STEWART, Christopher. Measuring information literacy: beyond the case study. The Journal of Academic Librarianship, v. 37, n. 3, p. 270-272, maio 2011.

THIOLLENT, M. Metodologia da pesquisa-ação. 15ạ. ed. São Paulo: Cortez, 2007.

TRIPP, David. Pesquisa-ação: uma introdução metodológica. Educação e Pesquisa, v. 31, n. 3, p. 443-366, 2005.

ZACCARO, Christiano Henrique. A arquitetura das organizações aprendentes. Taubaté: Cabral, 2003. 